\title{
Synthesis of Some Alkyl Polyglycosides
}

\author{
Ramazan Donat (iD) 1,*, Volkan Demirel (iD) 1
}

${ }^{1}$ Pamukkale University, Faculty of Arts and Sciences, Department of Chemistry, Denizli, Turkiye

\begin{abstract}
Surfactants are indisputably more important today, in terms of their use in industry and daily life, as well as the tasks they perform. In recent years, due to the driving force of environmental concerns, orientations to alternatives of surfactants that cause less or no harm to the environment have accelerated. One of these trends is the synthesis of alkyl polyglycosides (APG) and their use in the detergent industry. In this study, different acidic catalysts were used for the synthesis of APGs and the highest yield was achieved with sulfuric acid. APGs with different carbon numbers were obtained using octanol, decanol, dodecanol, and octanol/cetyl alcohol (w/w 80/20). The FTIR spectra of the structures of APG products obtained with these fatty alcohols and some commercial APG products were compared, and their structures were elucidated. In addition, the foam quality of the obtained APGs and the hydrophilicity properties they impart to the textile material were compared with some commercial surfactants, and the results were interpreted and evaluated.
\end{abstract}

\section{ARTICLE HISTORY}

Received: Dec. 07, 2021

Revised: Feb. 08, 2022

Accepted: Feb. 16, 2022

\section{KEYWORDS}

Surfactants,

Butyl glycoside,

Alkyl polyglycoside,

Synthesis,

APG reaction mechanism

\section{INTRODUCTION}

Surfactants are chemicals that change the surface tension in the solution to which they are added and often reduce the surface tension. The molecules of a liquid attract each other due to dispersion, dipole-dipole, dipole-excited dipole, and hydrogen bonds. A molecule in a liquid mass exhibits the same attractive and repulsive forces in all directions. But on the surface, a direction of these forces is missing. This asymmetry of forces is the source of surface energy, or surface tension (Pispanen, 2002).

At the molecular level, surfactants are organic compounds containing at least one lipophilic (solvent-loving) and one lipophobic (solvent-loving) group. If the solvent in which surfactants will be used is water or an aqueous solution, these terms are called hydrophilic and hydrophobic, respectively (Rosen \& Dahanayake, 2000).

Surfactants classified according to the sign of the charge at the hydrophilic ends are grouped as anionic, non-ionic, cationic, and amphoteric and are demanded by users considering the unique characteristics of each group. Alkyl polyglycosides, which we have been working on, non-ionic APGs are surfactants. The use of non-ionic surfactants accounts for $40 \%$ of the world's use of surfactants (Schmitt, 2001).

\footnotetext{
*CONTACT: Ramazan Donat $\bigotimes$ rdonat@pau.edu.tr
} Pamukkale University, Faculty of Arts and Sciences, Department of Chemistry, Denizli, Turkiye 
Alkyl polyglycoside (APG) is a surfactant made from renewable natural ingredients, namely carbohydrates and fatty alcohols. APG can be used as an additive in the formulation of several products such as herbicides, personal care products, cosmetics, and fabric/textile bleaching. Alkyl polyglycosides are non-ionic surfactants because the polar (hydrophilic) and non-polar (hydrophobic) groups have no charge. Its hydrophobic nature is found in the alkyl groups of fatty alcohols and its hydrophilic nature is found in the glucose molecule. This APG surfactant is harmless to the eyes, skin, and membranes, reduces the irritant effect, and can decompose well aerobically and anaerobically (Mehling et al., 2007).

APG surfactants can be produced by the Fischer method directly (acetalization) and indirectly through two stages, namely butanolysis and trans acetalization, and then through the stages of neutralization and distillation. The synthesis of APG through a two-step process using glucose and fatty alcohols with different chain lengths has been carried out by Ware et al. (2007) with 5 different carbon chains, namely octanol (C8), decanol (C10), dodecanol (C12), hexadecanol (C16), and octadecanol (C18) and El-Sukkary et al., (2008) with different alkyl chain lengths, namely octanol (C8), nonanol (C9), decanol (C10), dodecanol (C12) and tetradecanol (C14).

Generally, the catalyst used is $p$-toluene-sulfonic acid (PTSA) (Ware et al., 2007; ElSukkary et al., 2008). In this study, an experiment was conducted using the MESA catalyst as an alternative catalyst that is more environmentally friendly and renewable than palm oil.

The saccharides that can be used to produce APG include glucose, fructose, mannose, galactose, xylose, starch, sucrose, lactose, and so on, both in liquid and solid form. The use of glucose and starch is more widely used for reasons of availability and low cost (O'Lenick, 2007). The process of making APG is still dominated by the use of potato and corn starch as hydrophilic groups and C14-C18 fatty alcohols as a source of hydrophobic groups (Hill, 2009). Research using sago starch has been carried out by Suryani et al. (2008) and tapioca by Bastian et al. (2012).

In this study, fatty alcohols of different chain lengths and alkyl polyglycoside surfactants were synthesized using the two-step trans acetylation method and these products were compared with their counterparts, which are widely used in the industry.

\section{MATERIAL and METHODS}

\subsection{Materials}

All chemicals used in the study are of analytical purity. Butanol, octanol, decanol, dodecanol, cetyl alcohol, $D-(+)$-glucose, sodium hydroxide, potassium hydroxide, sulfuric acid, metaphosphoric acid, $p$-toluene sulfonic acid, methanol, and potassium hydroxide chemicals were obtained from Merck and Aldrich companies.

\subsection{Preparation of APGs}

A number of APGs were synthesized using fatty alcohols of different alkyl chain lengths to produce surfactant compounds.

\subsubsection{Indirect method}

Three different chemical substances (sulfuric acid, meta-phosphoric acid, and $p$-toluene sulfonic acid) were used in the catalyst selection. Anhydrous glucose and butanol were mixed in different proportions and mixed at a constant speed with a mechanical mixer in the apparatus shown in Figure 1, in the presence of a catalyst, in the temperature range of $80-120^{\circ} \mathrm{C}$. During this time, Fehling's solution was used to determine the amount of glucose in the sample taken from the reactor balloon. Unreacted fatty alcohols were distilled under a vacuum in a rotary evaporator. In the synthesis of APG, catalysts such as $p$-toluene sulfonic acid, sulfuric acid, and meta-phosphoric acid were used for each separate experimental process. In the first step, the 
reaction method was selected for the convenience of our experimental studies in the APG synthesis process. In general, from the information we obtained from our literature research, it was determined that two types of methods were used, namely, one-step and two-step synthesis methods. The single-step reaction method requires less equipment. However intermediate product, butyl glycoside, is a stable compound to start to combine long-chain fatty alcohol and glycose part, and the yield of the overall reaction is higher in two-step synthesis. Therefore, in this study for the synthesis of APGs, it was decided to work with the two-step synthesis method.

Figure 1. Experimental setup used in the synthesis of butyl-glycoside and alkyl polyglycosides.

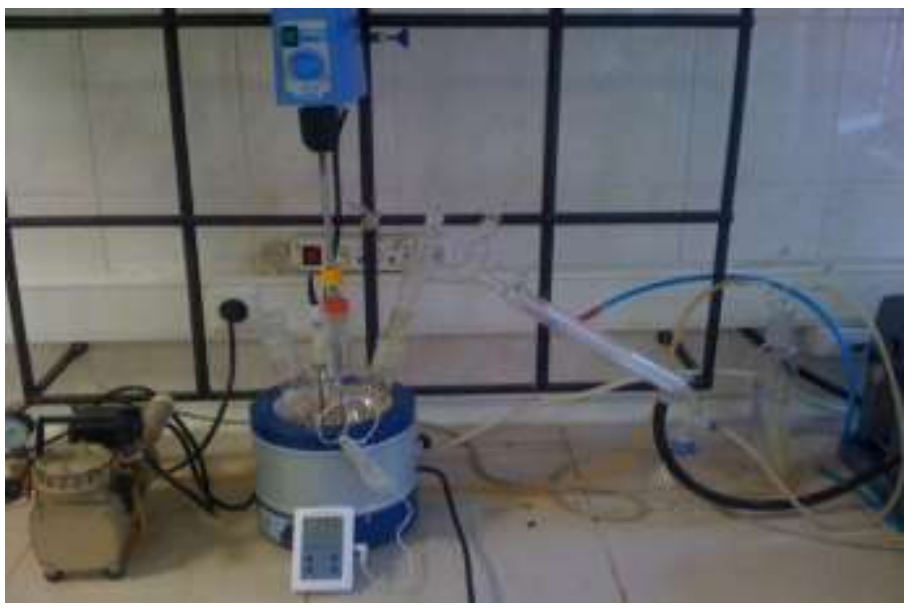

\subsection{Tests Applied to Synthesized Products}

\subsubsection{Structure confirmation of APGS}

The structure of the prepared compounds was confirmed by: Fourier transform infrared spectroscopy (FTIR) spectra using a Perkin Elmer UATR Two Model spectrophotometer.

\subsubsection{Foam test}

Each surfactant solution was prepared as $1 \mathrm{~g} / \mathrm{L} .50 \mathrm{~mL}$ of this solution was taken in a $100 \mathrm{~mL}$ mixing cylinder and shaken 50 times in 30 seconds. By removing the cover of the cylinder, the foam level was measured with a ruler. Foam strength was checked by measuring the foam level at 1-minute intervals.

\subsubsection{Hydrophility test}

Wetting power can be defined as the effective reduction of surface tension under dynamic conditions. During wetting, surfactant molecules must diffuse rapidly to the boundary between the moving liquid and the surface (Holmberg et al., 2002). The wetting abilities of surfactants are examined by the Draves test (Draves \& Clarkson, 1931).

$500 \mathrm{~mL}$ of $0.70 \mathrm{~g} / \mathrm{L}$ wetting solution is poured into a $500 \mathrm{~mL}$ mixing cylinder and it is waited for a while for the solution to become inactive. If there was foaming on the solution surface, waited until it disappeared. The textile sample, together with the weight, is kept at the mouth level of the mixing cylinder, left on the solution surface, and the chronometer is started as soon as it is released. When the fabric is completely wet and sinks to the bottom, the stopwatch is stopped and the result is recorded.

\section{RESULTS and DISCUSSION}

\subsection{Catalyst Effect and Selection in Butyl Glycoside Synthesis}

As a result of all these trials, it was seen that sulfuric acid was the most advantageous catalyst in terms of homogeneous mass transfer and in various temperatures. The FPG yields obtained for these three mineral acids were found to be around $70 \%$. The results of the studies on this 
subject support the results of our experiments. Xinping et al., 1999, reported that the best catalyst was sulfuric acid when the reaction times and yield were considered together. However, when $p$-toluene sulfonic acid is used, the amount of alkali required for neutralization is less, which means a product containing a lower concentration of salt (Xinping et al., 1999).

\subsection{Butyl polyglycoside synthesis}

In the APG synthesis study, $44.4 \mathrm{~g}$ anhydrous $D-(+)$-glucose $\left(\mathrm{C}_{6} \mathrm{H}_{12} \mathrm{O}_{6},\right)$ and $56.6 \mathrm{~g}$ n-butanol $\left(\mathrm{C}_{4} \mathrm{H}_{10} \mathrm{O}\right)$ were used as basic raw materials. $D-(+)$-glucose and n-butanol were placed in a fournecked balloon placed in a jacketed heater. After connecting the mechanical stirrer, thermometer, and reflux condenser (cooler) to the four-necked flask, the mixture containing $D$ (+)-glucose and n-butanol was mixed at $350 \mathrm{rpm}$ (Renhua et al., 1999). It is expected to reach the desired constant temperature $\left(105^{\circ} \mathrm{C}\right)$.

Temperature control is one of the most important parameters in the synthesis of butyl glycoside and APG. While the reaction mixture is in dispersion, glucose can be cooked at $120^{\circ} \mathrm{C}$ and above and caramelized. Xinping et al. (1999) emphasized that the reaction efficiency of working at high temperatures $\left(115^{\circ} \mathrm{C}\right)$ is high, but it should be taken into account that a sudden increase in temperature in the solution environment may cause glucose to cook (Xinping et al. 1999). At the beginning of our experimental studies, we started our reaction by starting from low values in order to keep the temperature stable, and by increasing the temperature over time and setting it to $105^{\circ} \mathrm{C}$, where the reaction can be realized most efficiently. After the mixture of $D$-(+)-glucose and n-butanol in the balloon were brought to a constant temperature, $0.13 \mathrm{~mL}$ of sulfuric acid was added into the balloon as a catalyst. The vacuum pump was operated at 200 $\mathrm{mmHg}$ and the water formed in the environment was taken with the help of reflux.

In this process, which was carried out at constant pressure and temperature, after about 30 minutes, the cloudy color of the solution lightened completely and became a transparent yellow solution. Fehling marker was used to detect the presence of glucose in the reaction medium. In order to terminate the reaction, $\mathrm{KOH}$ solution was added into the solution and allowed to cool so that the $\mathrm{pH}$ value of the solution, which was approximately $\mathrm{pH} 4$, was carried to between 810. The synthesized butyl-glycoside reaction mixture was filtered through a Buchner funnel with the help of a vacuum pump. The solvent in the obtained product was removed with the help of a rotary evaporator under a vacuum. The reaction of the synthesized butyl-glycoside is given in Figure 2 and the FTIR spectrum is given in Figure 3.

Figure 2. The reaction of butyl polyglycoside synthesis.
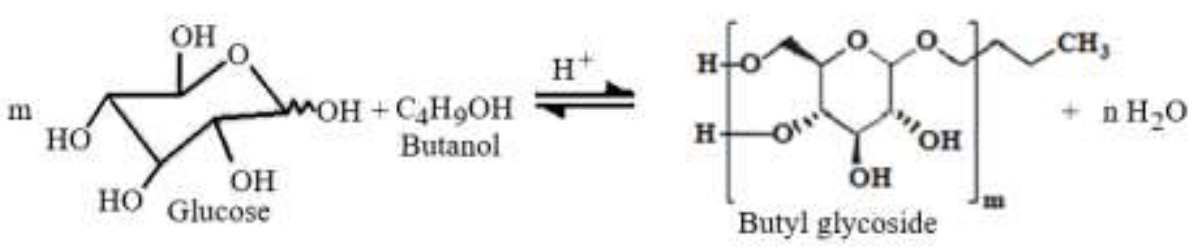

It is seen that there are characteristic different peaks in the FTIR spectrum of butyl glycoside (Figure 3). The characteristic signal for the $\mathrm{O}-\mathrm{H}$ group was between 3600 and $3200 \mathrm{~cm}^{-1}$, the asymmetric stretching vibration frequency of the $\mathrm{CH}_{3}$ and $\mathrm{CH}_{2}$ group, the symmetrical stretching vibrations of the other $\mathrm{CH}_{2}$ group were observed at 2960, 2933, and $2873 \mathrm{~cm}^{-1}$, respectively.

The vibration signal of the unbonded C-C bond can be observed around $1639 \mathrm{~cm}^{-1}$. Asymmetric bending vibration of $\mathrm{CH}_{2}$ group, asymmetric bending vibration of $\mathrm{CH}_{3}$ group and symmetrical bending vibration of $\mathrm{CH}_{3}$ group were detected at 1462,1416 , and $1378 \mathrm{~cm}^{-1}$, respectively (Kurashima et al., 2003; El-Sukkary et al., 2008). The vibration frequency seen at $1727 \mathrm{~cm}^{-1}$ indicates the presence of the butyl methyl group and the presence of hemiacetal $\mathrm{H}$ 
(where $\mathrm{H}$ is attached to the glycosylated carbon). The peak seen at $1100 \mathrm{~cm}^{-1}$ confirms that the glycoside product contains apo-glucosidase identified by etherification (Yu et al., 2008). It is seen that the ether formation in the structure is at $1170 \mathrm{~cm}^{-1}$ with a typical signal (Kurashima et al., 2003; El-Sukkary et al., 2008). Some properties of the synthesized butyl glycoside are given in Table 1.

As can be seen from Table 1, the melting point also increased, which may be due to the increase in the glycoside alkyl chain length and the van der Waals force between this chain.

Figure 3. FTIR spectrum of butyl glycoside.

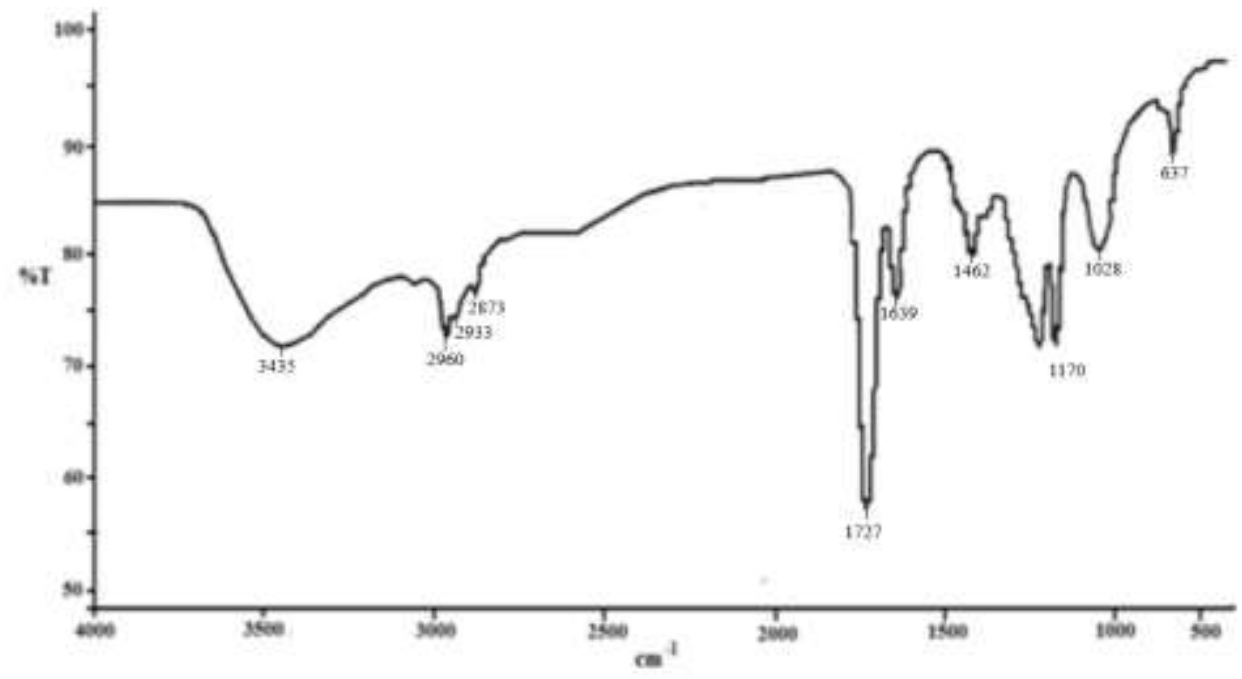

Table 1. Properties of experimentally synthesized butyl glycosides.

\begin{tabular}{lll}
\hline Physical characteristics & Solvent type & Butyl glycoside \\
\hline Organoleptic analysis & - & $\begin{array}{l}\text { Solid, light yellow, } \\
\text { odorless, sticky, creamy }\end{array}$ \\
Melting point & - & $52-58^{\circ} \mathrm{C}$ \\
Dissolution $25^{\circ} \mathrm{C}$ & Water & $>\% 20$ \\
& Pyridine & $>\% 20$ \\
& Glycerine & $\% 20-\% 1$ \\
& Carbon tetra chloride & $<1 \%$ \\
& Acetone & Stratified \\
& Petroleum ether & $<\% 1$ \\
\hline
\end{tabular}

\subsection{Synthesis of Dodecyl Polyglycoside}

In the synthesis study of 1-dodecanol polyglycoside, butyl polyglycoside, which was previously synthesized and subjected to the necessary separation and purification processes, was used as the basic raw material. For the synthesis of dodecyl polyglycoside, $50 \mathrm{~g}$ of butyl polyglycoside and $100 \mathrm{~g}$ of 1-dodecanol were put into the experimental setup given in Figure 1. After the necessary connections (refrigerant, thermometer, etc.) of the experimental setup were made, the temperature of the mixture was adjusted to be between $105-120^{\circ} \mathrm{C}$. The mixture containing butyl polyglycoside and 1-dodecanol was mixed at $500 \mathrm{rpm}$ and waited for the system to reach the desired constant temperature $\left(105-120^{\circ} \mathrm{C}\right)$. After the mixture of butyl polyglycoside and 1dodecanol in the balloon was brought to a constant temperature, $0.40 \mathrm{~mL}$ of sulfuric acid was added into the balloon as a catalyst. After the catalyst was added, the temperature in the balloon was adjusted to $110 \pm 5^{\circ} \mathrm{C}$ and a vacuum distillation connection was made at the same time to 
separate the water in the system. The vacuum pump was operated at a pressure of $200 \mathrm{mmHg}$ and the water formed in the environment was taken with the help of reflux. It was studied for four hours to complete the reaction. At the end of this period, potassium hydroxide dissolved in methanol was used to neutralize the $\mathrm{pH}$ of the solution. Base addition was continued until the $\mathrm{pH}$ value of 7.0 was reached. In order to purify the product, the unreacted fatty alcohols were removed from the environment by vacuum distillation in a way that the temperature would not exceed $140^{\circ} \mathrm{C}$ in the system where the vacuum pump was connected to the reflux. When the advent of the fatty alcohol was stopped by vacuum distillation, the process was terminated and the synthesized dodecyl polyglycoside mixture was left to cool. The synthesis reaction of the obtained dodecyl polyglycoside is given in Figure 4 and the FTIR spectrum is given in Figure 5.

Figure 4. Two-step APG synthesis process.

I. Glycidation step (butanylation)

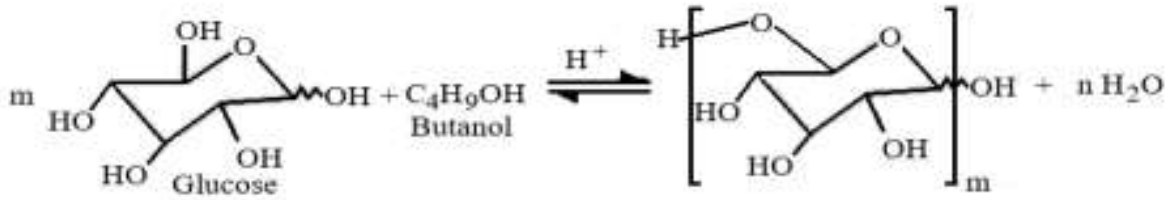

II. Transglycolysis step (transacelization)

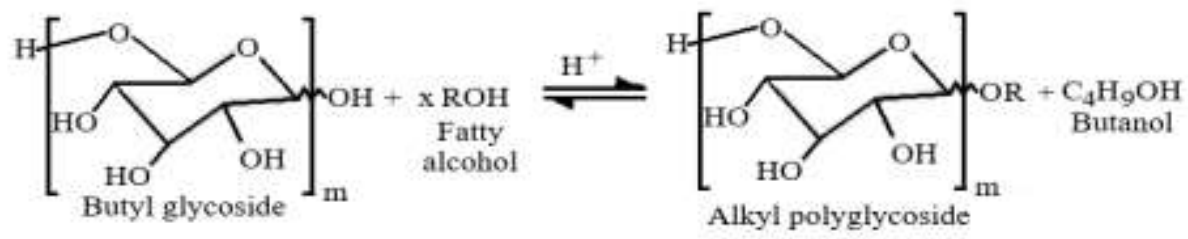

Figure 5. FTIR spectrum of synthesized dodecyl polyglycoside.

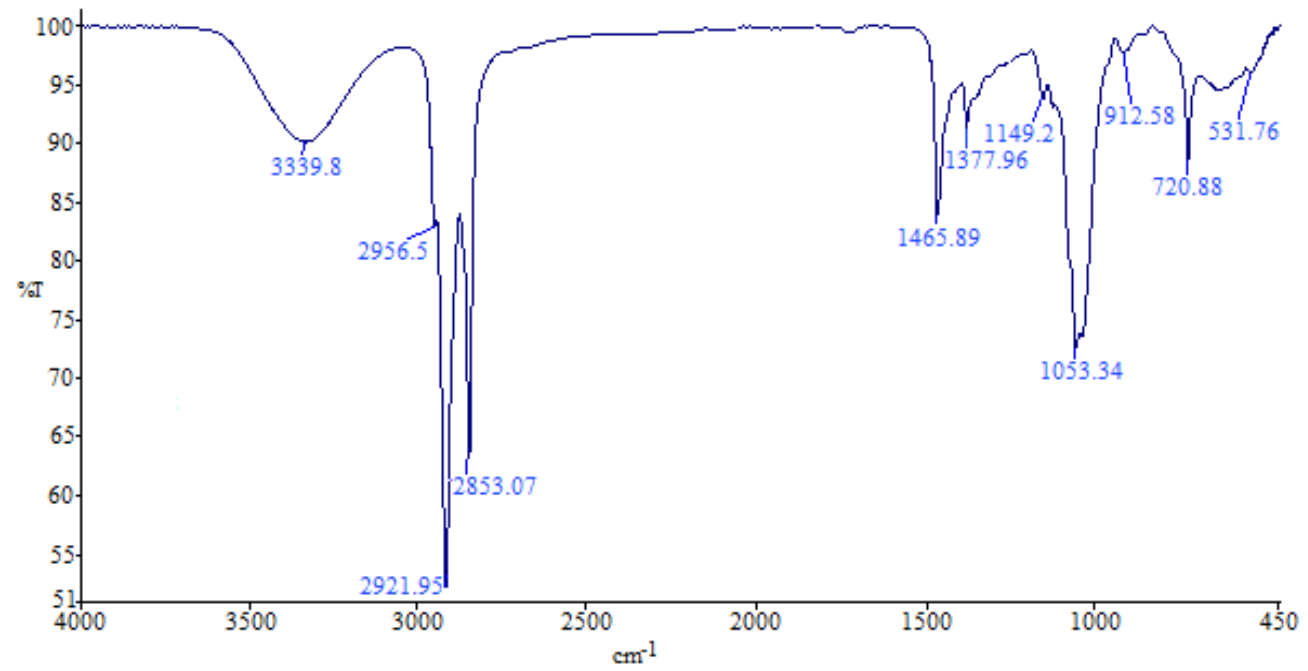

From the FTIR spectrum of the obtained alkyl polyglycoside (Figure 5), $2924 \mathrm{~cm}^{-1}$ shows the $\mathrm{C}-\mathrm{H}$ and $3361 \mathrm{~cm}^{-1}$ shows the vibration peak of the $\mathrm{O}-\mathrm{H}$ group. It is observed from the FTIR spectrum that it belongs to the polyglycoside alkyl formation from the $\mathrm{C}-\mathrm{O}$ vibration peak at $1032 \mathrm{~cm}^{-1}$. Looking at the spectrum of C-O-C ether formation, it is understood that dodecyl poly glycoside surfactants, acetylated glucose, and 1-dodecanol can be obtained by this synthesis method. The wavenumbers of both the $\mathrm{OH}$ and ether groups of the synthesized dodecanol polyglycoside are within the limits specified in the literature. According to the FTIR results of this APG obtained, it shows that ether groups $(\mathrm{C}-\mathrm{O}-\mathrm{C})$ functional groups are formed 
together with fatty alcohols, the OH group has a hydrophobic structure, and APG is synthesized through the hydroxyl groups of glucose. Some physical and chemical properties of dodecyl polyglycoside are given in Table 2.

Table 2. Properties of experimentally synthesized dodecyl alkyl polyglycoside.

\begin{tabular}{lll}
\hline Physical characteristics & Solvent type & Dodecyl polyglycoside \\
\hline Organoleptic analysis & - & Solid, brown, odorless, sticky, creamy \\
Melting point & - & $108-114^{\circ} \mathrm{C}$ \\
Dissolution $25^{\circ} \mathrm{C}$ & Water & $>\% 20$ \\
& Pyridine & $>\% 20$ \\
& Glycerine & $\% 20-\% 1$ \\
& Carbon tetra chloride & $<1 \%$ \\
& Acetone & Stratified \\
& petroleum ether & $<\% 1$ \\
\hline
\end{tabular}

As can be seen from Table 2 as the glycoside alkyl chain length increased, the melting point increases due to the van der Waals force between the chains.

In Table 3, some other properties of experimentally synthesized butyl glycoside and dodecyl polyglycoside with other surfactants are given comparatively. It is seen from Table 3 that dodecyl polyglycoside has lower surface tension and a higher foam height and excellent surface activity than other surfactants. On the other hand, it is seen that butyl glycoside basically does not have surface activity properties.

Table 3. Comparison of experimentally synthesized butyl and dodecyl polyglycoside with other surfactants (Test conditions: $1 \%$ aqueous solution, $30^{\circ} \mathrm{C}$ ).

\begin{tabular}{lcccl}
\hline Surfactants & $\begin{array}{c}\text { Bubble } \\
\text { height }\end{array}$ & $\begin{array}{c}\text { Surface tension } \\
(\mathrm{Dyn} / \mathrm{cm})\end{array}$ & $\begin{array}{c}\text { Foam } \\
\text { resistance }\end{array}$ & $\begin{array}{c}\text { Bubble } \\
\text { state }\end{array}$ \\
\hline Butyl polyglycoside & 35 & 0.6451 & Not good & Elegant, small quantities \\
Dodecyl polyglycoside & 195 & 0.3461 & Good & Elegant, large quantities \\
Sodium dodecyl sulfate & 220 & 0.4889 & Good & Bubble big, large quantities \\
OP-10 & 220 & 0.4283 & Good & Bubble big, large quantities \\
\hline
\end{tabular}

\subsection{APG Synthesis with Different Fatty Alcohols and Fatty Alcohol Mixtures}

As mentioned in Section 3.2.3, the procedures applied in the dodecyl polyglycoside synthesis method were repeated with octanol, decanol, and an octanol/cetyl alcohol mixture adjusted to $80 / 20(\mathrm{w} / \mathrm{w})$ by weight, instead of 1 -dodecanol. The synthesis of four different alkyl group polyglycosides was made by taking the ratios of butyl glycoside and other alcohols as $1 / 2$ by weight, respectively. The FTIR spectra of these four different alkyl polyglycosides are given in Figure 6, respectively.

FTIR spectroscopy analysis provides information about the presence of functional groups present in the molecule. The vibration of each functional group is observed at different wavelengths. The approximate frequencies at which organic functional groups (such as $\mathrm{C}=\mathrm{O}$, $\mathrm{CH} 3, \mathrm{C} \equiv \mathrm{C}$ ) absorb IR radiation can be calculated from the atomic masses and the bond constant between them. These are called group frequencies and can change when one or both atoms in the group are affected by other vibrations. The frequency ranges and bond vibration properties of organic groups of synthesized APGs are given in Table 4. 
Figure 6. FTIR spectrum of octyl, decyl, and cetyl/octyl polyglycoside.
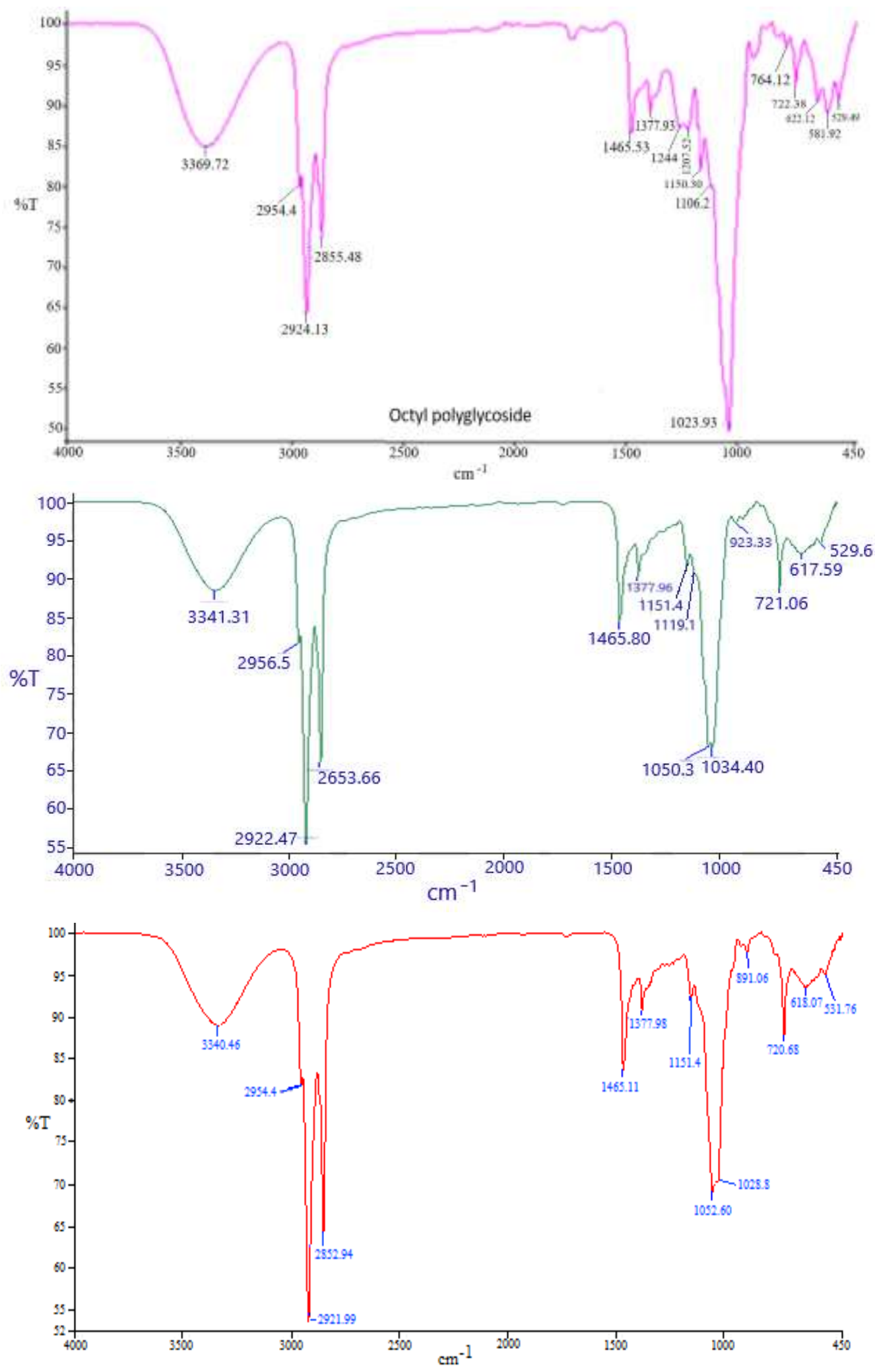
Table 4. Characteristic peaks of the prepared alkyl polyglycosides (APGs).

\begin{tabular}{lccc}
\hline & \multicolumn{3}{c}{ Wave Number $\left(\mathrm{cm}^{-1}\right)$} \\
\cline { 2 - 4 } Function group & $\begin{array}{c}\text { Octyl } \\
\text { polyglycoside }\end{array}$ & $\begin{array}{c}\text { Decyl } \\
\text { polyglycoside }\end{array}$ & $\begin{array}{c}\text { Cetyl/Octyl } \\
\text { polyglycoside }\end{array}$ \\
\hline $\mathrm{CH}_{2}$ & & & \\
\hline Multiple $\left(\mathrm{CH}_{2}\right)_{n}$ rock & 722.38 & 721.06 & 720.68 \\
Asymmetric bending & 1465.3 & 1465.80 & 1465.11 \\
Symmetric stretch & 2855.48 & 2653.66 & 2852.94 \\
Asymmetric stretch & 2924.13 & 2922.47 & 2921.99 \\
\hline $\mathrm{CH}_{3}$ & & & \\
\hline Symmetric bending & 1377.98 & 1377.96 & 1377.97 \\
Asymmetric bending & 1465.13 & 1465.80 & 1465.11 \\
Symmetric stretch & & & \\
Asymmetric stretch & 2954.4 & 2956.50 & 2954.4 \\
\hline O-H & 3369.72 & 3341.31 & 3340.46 \\
C-O & 1023.93 & 1034.40 & 1052.60 \\
Ether linkage & 1150.30 & 1151.40 & 1151.40 \\
\hline
\end{tabular}

It was observed that the O-H absorption wave number of octyl polyglycoside was 3369.72 $\mathrm{cm}^{-1}$, the $\mathrm{O}-\mathrm{H}$ group of decyl polyglycoside was $3341.31 \mathrm{~cm}^{-1}$ and the $\mathrm{OH}$ group of cetyl/octanol polyglycoside was $3340.45 \mathrm{~cm}^{-1}$. Sukkary et al., 2007, stated that the wavenumber of this absorption O-H group varies between $3200-3400 \mathrm{~cm}^{-1}$ and the absorption wavenumbers of the ether groups (C-O-C), which is the main component in the group of alkyl-polyglycosides, occur within 1120-1170 $\mathrm{cm}^{-1}$. The wavenumbers of both $\mathrm{O}-\mathrm{H}$ and ether groups of these three synthesized alkyl polyglycosides are within the limits specified in the literature. The FTIR results of these three APGs show that ether groups (C-O-C) have functional groups together with fatty alcohols, the O-H group has a hydrophobic structure, and APG is synthesized through the hydroxyl groups of glucose.

Two commercially available APG samples were provided to compare the alkyl polyglucose structure we synthesized. FTIR spectra of two different products, whose trade names are Triton and Milcoside, were taken and it was investigated whether there was a structural similarity with the products we synthesized. The FTIR spectra of these products are given in Figure 8, respectively.

It is seen that there are very close similarities between the commercial alkyl polyglycosides and the FTIR spectra of the synthesized alkyl polyglycosides. While the ether (C-O-C) groups in the APG we have synthesized have a wave absorption of 1149.20, the ether (C-O-C) groups of the commercial APGs have a wave absorption of 1150.17 and $1150.67 \mathrm{~cm}^{-1}$. When the wave absorptions of the $\mathrm{OH}$ groups are compared, the wave absorptions of commercial APGs are 3351.39 and $3351.48 \mathrm{~cm}^{-1}$, while the wave absorption of the synthesized APGs is $3339.8 \mathrm{~cm}^{-1}$. The formation of ether groups indicates that the synthesis between glycosides and fatty alcohols has taken place and the structure of hydrophobic groups has been formed, whereas the $\mathrm{OH}$ groups indicate the hydrophilic groups of APG. 
Figure 8. FTIR spectrum of Triton BG 10 and Milkoside 101 alkyl polyglycoside.
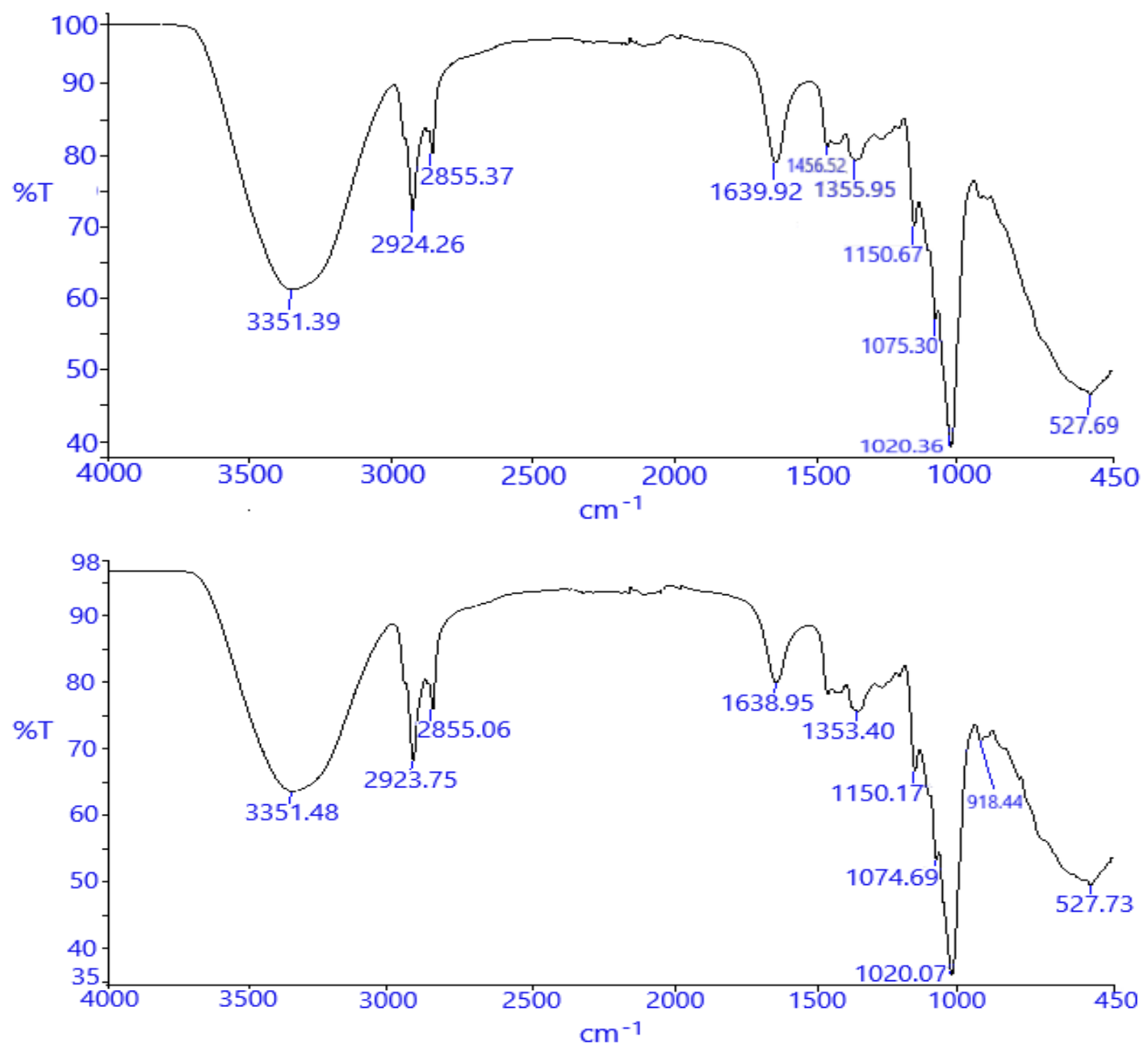

Four different poly alkyl polyglycoside (Butyl, Hexyl, Octyl, and Dodecyl polyglycoside) products were dissolved in chloroform-d $\left(\mathrm{CDCl}_{3}\right)$ solvent and their ${ }^{1} \mathrm{H}$ NMR spectrum is shown in Figure 9. The peaks of $\delta 0.875,1.250$, and $1.600 \mathrm{ppm}$ belong to the three protons of the methyl group (A1), the sixteen protons of methylene group (A2, A3, A4, A5, A6, A7, A8, A9), and the four protons of the methylene group (A10, A11), respectively. The one proton of the glucose ring (B6) linked to the hydroxyl group of 1-dodecanol is shown in the peak of $\delta 5.080$ $\mathrm{ppm}$. The peaks in the range from $\delta 3.840$ to $4.310 \mathrm{ppm}$ are a result of the other twelve protons (A12, B1, B2, B3, B4, B5, C1, C2, C3, C4). The peaks of the ${ }^{1} \mathrm{H}$ NMR spectrum are in accordance with the molecular structure of dodecyl polyglycosides (Chen et al., 2019). 
Figure 9. ${ }^{1} \mathrm{H}$ NMR spectrum of the butyl polyglycoside, hexyl polyglycoside, octyl polyglycoside, and dodecyl polyglycoside poliglucosides.
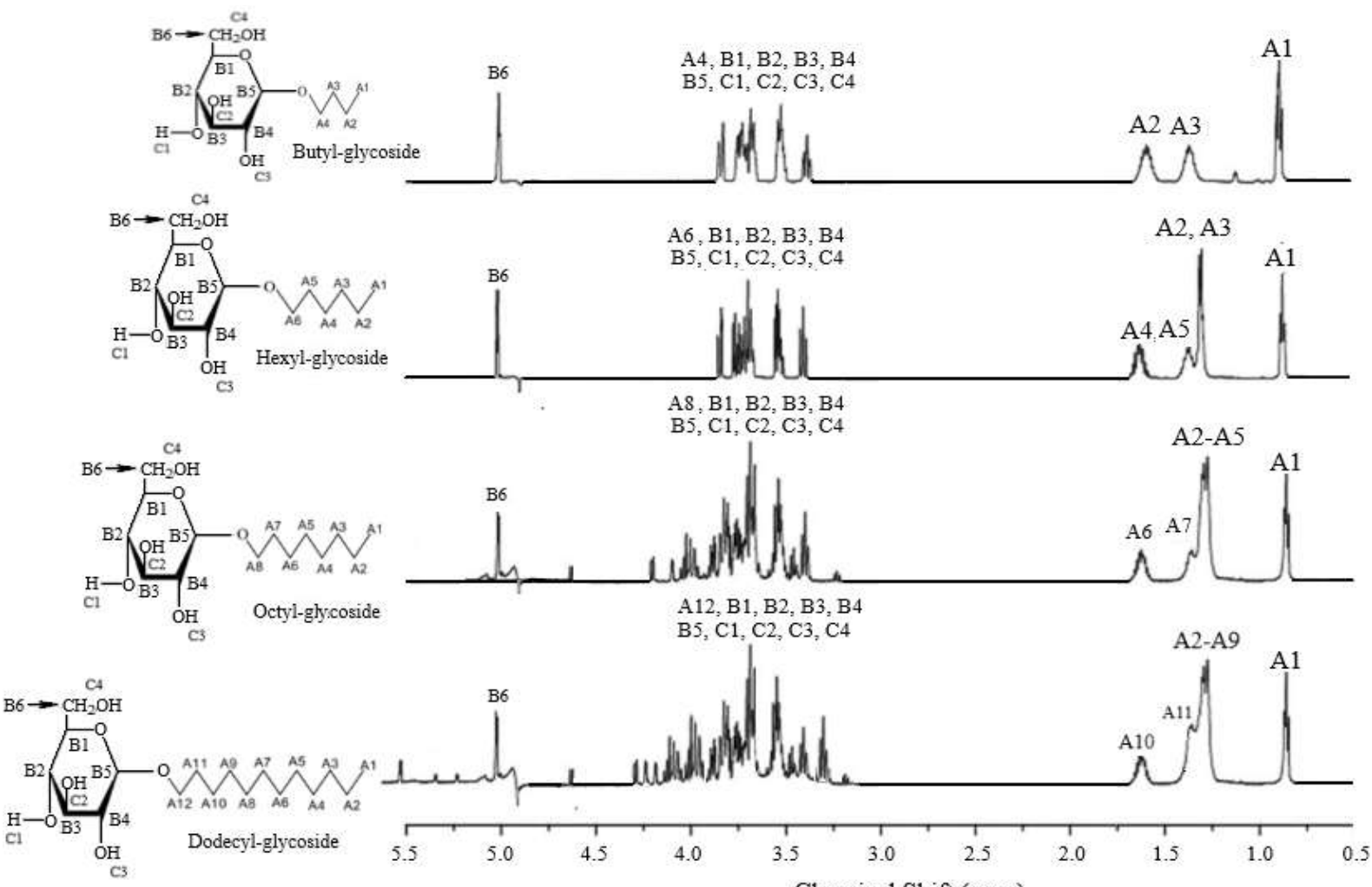

\subsection{Tests Applied to Synthesized Products}

\subsubsection{Foam test}

In this test, the foam characteristics of the synthesized alkyl polyglycoside and five different surfactants were compared. The tests were carried out on the same day and time zone, with the same measuring tape, using distilled water from the same container. Surfactants used in the tests; SLES (Sodium lauryl ether sulfate) Galaxy Surfactant Ltd. company, Milcoside 101 (APG produced with the octanol-decanol mixture) Elotan brand commercial purity product, Triton BG 10 (APG produced with octanol-decanol mixture) Triton brand commercial purity product, NP10 (Nonylphenol ethoxylate) Tergitol brand commercial pure product, LABSA (Linear alkylbenzene sulfonate) Hayat Kimya is commercially pure products. The results obtained as a result of the tests are given in Table 5 and Figure 10.

Table 5. Variation of foam amounts according to time as a result of foam test.

\begin{tabular}{|c|c|c|c|c|c|c|c|}
\hline \multirow{2}{*}{ Surfactants } & \multicolumn{6}{|c|}{ Time (min) } & \multirow{8}{*}{ 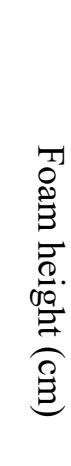 } \\
\hline & 0 & 1 & 2 & 3 & 4 & 5 & \\
\hline Oktyl polyglikoside & 15 & 7.0 & 6.2 & 5.0 & 3.8 & 3.7 & \\
\hline Milcoside 101 & 20 & 13.5 & 9.0 & 5.0 & 2.0 & 0.5 & \\
\hline Triton BG 10 & 21 & 13 & 9.0 & 4.5 & 1.0 & 0.3 & \\
\hline NP 10 & 16 & 1.9 & 0.0 & 0.0 & 0.0 & 0.0 & \\
\hline LABSA & 19 & 0.6 & 0.0 & 0.0 & 0.0 & 0.0 & \\
\hline SLES & 18 & 2.0 & 1.0 & 0.6 & 0.5 & 0.5 & \\
\hline
\end{tabular}


Figure 10. Graphical comparison of foam test results.

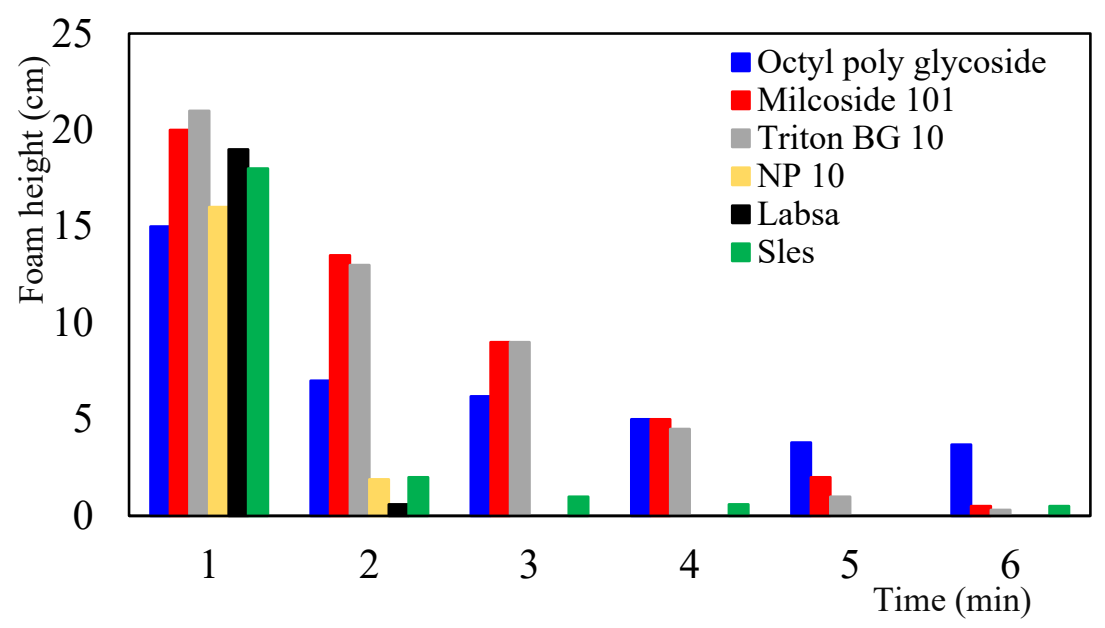

Considering the foam formations in the first moment of our tests, commercial APG samples gave the highest results. When the foam structure is compared with the well-known and most widely used alternatives such as SLES, LABSA, NP10, the foams of APGs are more stable, small, and late-extinguishing, while the foam structures of the others are large and less durable.

Although the foam heights of the products we obtained as a result of our synthesis studies are not as high as the commercial alternatives, better results were obtained in terms of foam permanence. The reason for the foam height difference between commercial APGs and synthesized APGs is thought to be the residual alcohols they contain. Alcohols generally affect the effects of foaming agents negatively and prevent foam formation.

The foam structure and the suitability of its permanence vary according to the sector and the product in which surfactants are used. While it is important that the foam is very permanent in products such as hand washing detergents, shampoos, and lipstick, the same situation is undesirable in textile chemicals and machine detergents used at home.

Shampoo formulations can be given as an example of situations where foam is particularly desired. In such products, the consumer wants a dense and creamy foam. Ether sulfates (especially SLES) have a foamy structure that goes out quickly. Therefore, a second cosurfactant is used to increase foam and viscosity properties in shampoos formulated with SLES. These foam boosters interact with the primary surfactant, reducing the electrostatic repulsion between the foam molecules by affecting the micelle structure. Thus, more permanent foams are formed.

\subsubsection{Hydrophility test}

Hydrophility is an important property sought in the fabric to be processed, especially in the textile industry. It is essential to add hydrophilicity to the fabric, which is handled as raw, in the pre-treatment processes. Because cotton, which is woven in its natural state and strengthened with sizing agents, is in a hydrophobic state due to natural oil residues and sizing agents. During the pre-treatment process, surfactant combinations, which are used under the name of "Wetting agents", take part in ensuring the penetration of caustic and peroxide into the fabric with water. Wetting agents are produced and used as a mixture of several surfactants, not from a single surfactant. In many biological and industrial applications, surfactant mixtures exhibit superior properties and superior micelle aggregation compared to their individual components.

The octyl glycoside product we obtained as a result of our synthesis studies was compared with SLES, NP10, LABSA, and the commercial equivalents of our product, Milcoside 101 and 
Triton BG 10. The data obtained as a result of the study are given in Table 6 below. Considering the ionic character from the values given in the table, it is obvious that the products we obtained have a wetting effect similar to NP10 in a non-ionic structure.

Table 6. Hydrophility test results.

\begin{tabular}{lc}
\hline Surfactant & Time (sn) \\
\hline SLES & 65 \\
NP10 & 30 \\
LABSA & 37 \\
Milcoside 101 & 143 \\
Triton BG 10 & 96 \\
Decyl polyglycoside & 30 \\
Dodecyl polyglycoside & 290 \\
Octyl polyglycoside & 23 \\
Octyl/cetyl polyglycoside & $<300$ \\
\hline
\end{tabular}

If we compare the synthesized products among themselves, as the carbon number of the alkyl group increases, the wetting ability decreases. The reason for this can be thought of as the difficulty of penetrating the large-molecule surfactant molecules, which facilitate the relationship between these two, by penetrating the oil-water interface.

\section{DISCUSSION and CONCLUSION}

The products obtained by this study are examined in terms of foam quality, which is the main feature possessed by surfactants, and their contribution to the hydrophility in the area they are used. All results show that their behaviors comply with described surfactant behaviors in the literature and they have properties close to other ready-made surfactants in the comparisons.

First of all, the structures of the obtained products were determined by FTIR measurements, and the results were compared with some commercial APGs. As a result of the comparison, it was seen that the synthesized products gave FTIR values close to the commercial products, and their structures were confirmed. Afterward, the synthesized products were evaluated with other commercial surfactants in terms of foam quality and hydrophilicity to the textile material. As a result of the foam tests, it has been observed that the foams of APGs are more stable, small, and late extinguishing, while the foam structures of other surfactant materials are coarse and their strength is less.

If the synthesized products are compared among themselves in terms of the hydrophilicity imparted to the textile material, it can be concluded that the wetting ability of the alkyl group decreases as the carbon number increases. As a result of the comparison of commercial APGs with other commercial surfactants, it was observed that they were weaker in terms of wetting ability.

\section{Acknowledgments}

This research project was financially supported by Pamukkale University as a Scientific Research Project (Project No: BAP 2012FEBE024).

\section{Declaration of Conflicting Interests and Ethics}

The authors declare no conflict of interest. This research study complies with research and publishing ethics. The scientific and legal responsibility for manuscripts published in IJSM belongs to the authors. 


\section{Authorship contribution statement}

Ramazan Donat: Investigation, Resources, Visualization, Software, Formal Analysis. Volkan Demirel: Writing-original draft, Methodology, Supervision.

\section{Orcid}

Ramazan Donat (iD https://orcid.org/0000-0002-5701-5030

Volkan Demirel (D) https://orcid.org/0000-0002-4998-1087

\section{REFERENCES}

Bastian, F., Suryani, A., \& Sunarti, T.C. (2012). Peningkatan kecerahan pada proses sintesis surfaktan non ionik alkil poliglikosida (APG) berbasis tapioka dan dodekanol. Reaktor Chem. Engineer. J., 14(3), 43-150. https://doi.org/10.14710/reaktor.14.2.143-150

Chen, J., Li, J., Liu, K., Hong, M., You, R., Qu, P., Chen, M. (2019). Subcritical Methanolysis of Starch and Transglycosidation to Produce Dodecyl Polyglucosides. ACS Omega, 4(15), 16372-16377. https://doi.org/10.1021/acsomega.9b01617

El-Sukkary, M.M.A., Syed, N., Aiad, I., \& El-Azab, W.I.M. (2008). Synthesis and characterization of some alkyl polyglycosides surfactants. J. Surfactants Deterg., 11(2), 129-13. https://doi.org/10.1007/s11743-008-1063-9

Hill, K. (2009). Alkyl polyglycosides-where green meets performance. Soft Journal, 2, 6-14

Kurashima, K., Fujii, M., Ida, Y., \& Akita, H. (2003). Enzymatic $\beta$-glycosidation of primary alcohols. J. Mol. Catal. B-Enzym., 26(1-2), 87-98. https://doi.org/10.1016/S13811177(03)00168-1

Mehling, A., Kleber, M., \& Hensen, H. (2007). Comparative studies on the ocular and dermal irritation of surfactants. Food Chem. Toxicol., 14, 747-758. https://doi.org/10.1016/j.fct.20 06.10 .024 .

O’Lenick, Jr. (2007). Non-ionic surfactant based upon Alkyl Polyglucosides. United States Patent, US7189683

Piispanen, P.S. (2002). Synthesis and Characterization of Surfactants Based on Natural Products. Master Thesis, Kungl Tekniska Högskolan, Stockholm

Renhua, L., Minghua, W., Zhuoru, Y., Xinping, Q., \& Huanqin, C. (1999). Reaction Kinetic Studies on the Synthesis of Alkyl Polyglycosides. Journal of South China University of Technology, (Natural Science), 27(4), 116-121

Rosen, M.J., \& Dahanayake, M. (2000). Industrial Utilization of Surfactant, Illinois: AOCS Press, $1-85$

Schmitt, T.M. (2001) Analysis of Surfactants. New York-Basel: Marcel Dekker Inc.

Suryani, A., Dadang, N., Setyadjit, N., Tjokrowardojo, A.S., Kurniadji, N., \& Noerdin, M. (2008). Sintesis alkilpoliglikosida (APG) berbasis alkohol lemak dan pati sagu untuk formulasi herbisida. Indonesian Journal of Agricultural Postharvest Research, 5(1), 10-20. https://doi.org/10.21082/jpasca.v5n1.2008.10-20

Xinping, Q., Renhua, L., Huang., L., Yang, Z., \& Chen, H. (1999). A Study on the Syntesis of Alkyl Polyglycosides. Journal of South China University of Technology, (Natural Science), 27(4), 87-91.

Ware, A.M., Waghmare, J.T., \& Momin, S.A. (2007). Alkylpolyglycoside: Carbohydrate based surfactant. J. Disper. Sci. Technol., 28, 437-444. https://doi.org/10.1080/019326906011078 07

Yu, J., Zhang, J., Zhao, A., \& Ma, X. (2008). Study of glucose ester synthesis by immobilized lipase from Candida sp. Catal. Commun., 9(6), 1369-1374. https://doi.org/10.1016/j.catco $\underline{\text { m.2007.11.036 }}$ 